\title{
Therapeutic intervention in patients with breast carcinoma, metastatic and her-2 over expression: case report
}

\begin{abstract}
Introduction: Breast cancer is the leading cause of death from cancer in women. Among the most common morphologies stands out associated with the HER-2 receptor whose over expression indicates more aggressive disease.

Objective: To report the changes to the treatment regimen used throughout the course of the disease in a patient with carcinoma patients with over expression of HER-2.

Case report: A female patient diagnosed since 2010 with infiltrating ductal carcinoma grade (CDI) 3 with micrometastases in lymph node and over expression of HER 2. In 2013, showed metastasis in right axillary region. She was, then, submitted to a lymphadenectomy, radiation therapy, followed by administration of Anastrozole. She was later diagnosed liver metastasis and fossa above right clavicle, starting chemotherapy with trastuzumab (Herceptin) and docetaxel Pertuzumab (PerjetaTM), obtaining initial response. However, in January 2015, liver injury progressed and after three cycles of chemotherapy with T-DM1 she had a partial regression. The patient still maintained the stable condition for another year during the current treatment until clinical worsening due to progression of liver metastases, and death due to complications of hepatic failure in the first half of 2016 .
\end{abstract}

Discussion: The patient therapy one of the targets against the HER-2 receptor was Herceptin, given in combination with Pertuzumab and Docetaxel. However, the short duration of event-free survival imposed changes in therapy from Capecitabine and Laparinibe. On the progression of liver injury was replaced the previous scheme by DM1 Trastuzumab, an antibody-drug conjugate. This conjugate showed a positive response in the outcome.

Conclusion: case report highlights the importance of discussion of new systemic therapies for the increase in overall survival of patients with breast carcinoma with overexpression of HER-2.

Keywords: breast cancer, infiltrate ductal carcinoma, her-2 positive, trastuzumab $\mathrm{dm} 1$
Volume 9 Issue 4 - 2018

\section{Ana Cristina Herrera,' Aline Garcia Ferrari, ${ }^{2}$ Cristiane França da Silva, ${ }^{2}$ Denise Camilios Cossiolo, ${ }^{2}$ Jhayanne Brunna de Costa ${ }^{2}$ 'A specialist in Oncology Surgery by the Brazilian Society of Cancerology, Lecturer in Medicine at the Pontifical Catholic University of Paraná (PUC-PR) Campus Londrina, Brazil ${ }^{2}$ Academic Professor of Medicine at the Pontifical Catholic University of Paraná (PUC-PR) Campus Londrina, Brazil}

Correspondence: Ana Cristina Herrera, A specialist in Oncology Surgery by the Brazilian Society of Cancerology, Lecturer in Medicine at the Pontifical Catholic University of Paraná (PUC-PR) Campus Londrina, Brazil, Email cristiane.francadasilva@gmail.com

Received: August 05, 2018 | Published: August 13, 2018

\section{Introduction}

Breast cancer is the type of malignant tumor that affects women all over the world and is the leading cause of death by cancer in women in both developing and developed countries. About 520,000 deaths were estimated for the year 2012 and approximately 1.67 million new cases of this neoplasm were expected worldwide. This represents $25 \%$ of all cancers diagnosed in women. Over the past 40years, survival has been increasing in developed countries and is currently $85 \%$ in five years, while in developing countries it remains between $50 \%$ and $60 \%{ }^{1}$ The classification of breast cancer is divided into two types: histopathological and molecular. Among the most common morphologic types of cancer, the HER2 receptor is physiologically very common in epithelial cells present in the breast tissue. In view of the overexposure of both receptors and HER2 / NEU genes, the appearance of HER2 positive breast cancer is an indication of disease aggressiveness and influences the prognosis and the predictive factor

${ }^{1}$ Instituto Nacional de Câncer José Alencar Gomes da Silva. Estimativa 2014 Incidência de Câncer no Brasil. Rio de Janeiro: INCA; 2014. of the therapeutics associated with it. ${ }^{2}$

The Brazilian study of the epidemiology of breast cancer helped to delineate its incidence in the female population. Azevedo and Mendonça were pioneers in demonstrating the incidence of the disease and its corresponding mortality in 1986, and Cecílio et al., ${ }^{3}$ described the epidemiological history of the disease in Brazil in the decade of 2010 , analyzing the advances in the screening of breast cancer by the different states of the country and the impact of the new therapies on the incidence of the disease.

Due to its high prevalence in the present day, the discussion of this disease, especially regarding the evolution of the treatment for breast cancer in metastatic patients, is essential.

${ }^{2}$ Katz A, Marques R, Novis Y. Oncologia Clínica Terapia Baseada em Evidências. 1st edition. Centro de Oncologia do Hospital Sírio Libanês, São Paulo; 2012; 260-266.

${ }^{3}$ Cecilio AP, Takakura ET, Jumes JJ, Santos JW, Herrera AC, Victorino VJ, et al. Breast cancer in Brazil: epidemiology and treatment challenges. Dove Med Press Limited 2015;(7):1-7. 
Santos ${ }^{4}$ looked at the importance of the incidence of new systemic therapies for increasing median overall survival of approximately two years for patients with metastatic breast cancer. And even in view of the arsenal available for the treatment of the disease, the metastatic disease, still incurable, has a median survival of 2 to 3years from the time of its discovery. Among the main sites of breast cancer metastasis are bones, skin, lymph nodes, lungs, pleura, liver and brain. ${ }^{4}$

The recommended staging system for breast cancer has been proposed by the American Joint Committee on Cancer (AJCC). The staging is grouped in TNM, being T (primary tumor); $\mathrm{N}$ (regional lymph nodes) and $\mathrm{M}$ (distant metastasis). ${ }^{5}$

Hepatic metastasis, especially secondary to breast cancer, is associated with more advanced stages of this cancer in $50 \%$ of the cases and may develop even after resection of the primary cancer. ${ }^{6}$ Among the most common symptoms are pain in the upper right quadrant, fever, weight loss, ascites and jaundice. Among the diagnostic modalities used are abdominal CT, CT with arterial portography, US of the liver, MRI and intraoperative US.

Routine serologic markers such as carcinoembryonic antigen (CEA), CA 19-9, human chorionic gonadotrophin (HCG) and 5-hydroxyindoleacetic acid (5-HIAA) help in liver function analysis and therefore also are extremely useful tools for the early diagnosis of this unfoldment, which make this routine so important for the maintenance of patient survival.

In breast cancer, it is a recurrence of HER-2 hyperexpression, which implies more aggressive clinical behavior of the tumor and reserved outcome. With the discovery of therapies based on molecular targets such as HER-2, conventional cytotoxic chemotherapy and hormone therapy, it was associated with more specific and sophisticated treatments. Monoclonal antibodies such as Trastuzumab make up this new target-directed therapy. This drug is standard for patients with metastatic breast cancer with HER-2 hyperexpression as it binds to extracellular regions of HER, interfering with receptor function and causing tumor involution. This allows an increase in the survival and quality of life of these patients, besides increasing the control of the disease when administered. The present article aims to evaluate how treatments based on HER-2 can increase disease-free time and the overall survival of patients in their use. ${ }^{8}$

\section{Case report}

Patient ACCB, 48years old, female, from Rancharia (SP), G3P2A1, menarche at age 9, diabetic (using Metformin) and with Hypercholesterolemia (using Simvastatin), has a family history of esophageal neoplasia (maternal grandfather) and colon (mother) neoplasia.

In March 2010 she had a diagnosis of high-grade invasive ductal carcinoma, discovered during some routine exams and from a Core biopsy of the right breast node. Later that month, she underwent

\footnotetext{
${ }^{4}$ Santos, A.S. Bevacizumabe e Câncer de mama. Revi Bras de Oncologia Clínica 2014; (36):67-70.

${ }^{5}$ Araujo LHL, Melo AC, Moreira MML, et al. Metástase Gástrica de Câncer de Mama: relato de caso e revisão de literatura. Rev bras cancerol. 2007; 53(3):365-8.

${ }^{6}$ Kalil AN; Severa C. Hepatectomia para metástases hepáticas de câncer de mama. Rev do Col Bras de Cirurgiões. 2005; 32(5): 285-6.

${ }^{7}$ Neto OCLF. Metástases Hepáticas. J. Bra de Medicina. 2014; (102): 29-33.

${ }^{8}$ Hoff PMG, Chammas R, Novis Y, Odoni Filho V. Tratado de oncologia, Atheneu, São Paulo;2013; ( 2) :2028-2029.
}

quadrantectomy with sentinel lymph node biopsy. The result of the anatomopathological examination showed a $1.8 \mathrm{~cm}$ histological grade (grade 3) Ductal Infiltrating Carcinoma (ICD) with free margins. Micrometastasis was also observed in $1 \mathrm{~T} 1 \mathrm{c}$ N1 mic staging lymph node. The immunohistochemical examination reported overexpression of HER 2, positivity to hormone receptors (estrogen receptor positive $50 \%$ ). She started radiotherapy and chemotherapy in 6 cycles of ACTH. In January 2011 he started using Tamoxifen.

In April 2013, the follow-up examination revealed the presence of metastases in the right axillary region, when axillary lymphadenectomy was indicated. There was also an evidence of involvement of 8 lymph nodes. After right axillary radiotherapy, the patient started using Anastrozole in August of that year. In March of the following year hepatic metastasis was found and in the right supraclavicular fossa. In April 2014 she started chemotherapy with Herceptin, Docetaxel and Pertuzumabe. After 3 cycles, partial response to treatment was noted, with total regression of lymph node metastasis in the supraclavicular fossa and approximately $50 \%$ of the dimensions of liver lesions. However, after the fifth cycle of the aforementioned therapeutic regimen, there was worsening of the general condition and abdominal pain, and imaging showed a progression of the disease. In August 2014 she started treatment with Capecitabine and Lapatinib. In January of 2015 the patient presented a new progression of the hepatic lesions in the validity of the treatment, when it was decided to change the therapy for T-DM1. Image exams after 3 cycles of treatment showed partial regression of liver lesions. The patient remained clinically stable for another year during the current treatment until clinical worsening due to progression of liver metastases and death due to clinical worsening due to complications of hepatic failure in the first half of 2016.

\section{Discussion}

One of the objectives of the treatment of mammary metastatic neoplasia is to improve survival and quality of life of the patient through the management of the symptoms presented. ${ }^{9}$ Overall survival, considered as the time elapsed between diagnosis and death, is considered as the most relevant therapeutic outcome before a therapeutic design. Event-free survival and time to progression are also important clinical outcomes because they provide data on the evolution of the disease as mortality rates related to neoplasia. ${ }^{10}$

The adoption of the best therapeutic parameter for the patients should take into consideration the tumor status of the HER2 / NEU oncogene expression, besides the presence or absence of menopause and evidence of expression of the hormonal receptors of the tumor, among them the estrogen and progesterone receptor. ${ }^{11}$ One of the major targets for the treatment of targeted HER family receptor consists of two classes of agents. One is based on monoclonal antibodies that act from their binding to extracellular regions of the HER, interfering with receptor function. The other class is composed of small tyrosine kinase inhibitor (ITK) molecules capable of inhibiting the enzymatic function of intracellular HER family members. ${ }^{12}$

\footnotetext{
${ }^{9}$ Murad AM.Tratamento do câncer de mama metastático: uma abordagem prática. Rev. Bras. Oncologia Clínica 2005; 1(4): 29-32.

${ }^{10}$ Machado KK, Katz A, Buyse M; Saad, E D. Sobrevida global e outros desfechos clínicos em câncer de mama: situação atual e controvérsias. Rev Assoc Med Bras 2010; 56(5): 493-516.

11 Murad AM.Tratamento do câncer de mama metastático: uma abordagem prática. Rev. Bras. Oncologia Clínica 2005; 1(4): 29-32.

${ }^{12}$ Katz A, Marques R, Novis Y, Rocha V, Costa FP, Fernandes G, et al. Oncologia Clínica Terapia Baseada em Evidências. $1^{\circ}$ ed., Centro de Oncologia do Hospital Sírio Libanês, São Paulo; 2012; 260-266.
} 
A large clinical trial called CLEOPATRA was published in 2012 and evaluated the benefit of the combination of Trastuzumab, Pertuzumab and Docetaxel for the treatment of metastatic breast cancer with amplified HER-2. This randomized study demonstrated that the use of the Pertuzumab, Trastuzumab and Docetaxel combination as a first line of treatment significantly improved the overall survival of patients with HER2-positive metastatic breast cancer compared to placebo associated with Trastuzumab and Docetaxel, providing a 15fold increase , 7 months in the median values. ${ }^{13}$

In the case of the patient, one of the targets against the HER 2 receptor was Trastuzumab (Herceptin), a drug used for the treatment of metastatic breast cancer with overexpression of HER-2. It can be used as both first-line therapy in combination with chemotherapy, and after chemotherapy for metastatic disease. ${ }^{14}$ Pertuzumab (Perjeta $\mathrm{TM}$ ), another monoclonal antibody administered in the patient, exhibits mechanism based on its binding to an HER-2 extracellular domain epitope, inhibiting HER-2 heterodimerization with EGFR and ErbB3. Its inclusion in the conduct is aimed at preventing intracellular signaling. ${ }^{15}$

The chemotherapeutic drug Docetaxel has been used in combination with Trastuzumab and Pertuzumab to stop the growth and proliferation of cancer cells. ${ }^{16}$ As reported, event-free survival lasted only three months, which led to a further change in the therapeutic regimen from Capecitabine and Laparinibe.

Lapatinib is an oral inhibitor that acts reversibly on EGFR and HER-2. This double blocking causes a more potent disruption of cell growth. In addition, Lapatinib dissociates more slowly from EGFR as compared to selective EGFR tyrosine kinase inhibitors, prolonging its effect. Lapatinib can be used in combination with Capecitabine for the treatment of advanced or metastatic mammary neoplasia where there is overexpression of HER-2 and have previously used Anthracyclines, Taxanes, and Trastuzumab. Labatinib may also be associated with Trastuzumab. A phase III clinical trial demonstrated that the progression-free survival time is longer when these two drugs are combined compared to the use of Lapatinib alone in a patient with metastatic breast cancer with pre-treated HER2 and who presented with progression after the use of Trastuzumab. ${ }^{17}$

In view of the progression of hepatic lesions, a new therapeutic approach was proposed replacing the previous scheme with Trastuzumab DM1, an antibody-drug conjugate based on the combination of Trastuzumab with DM1 (also called Maitansine), an antimicrotubule drug. This association helps the anti-HER-2 activity, in addition to enabling the intracellular distribution directed to a potent cytotoxic agent. The benefit of this compound lies in the fact

\footnotetext{
${ }^{13}$ Baselga J, Cortés J, Kim SB, Hegg R, Roman L, Pedrini JL, et al. Pertuzumab plus Trastuzumab plus Docetaxel for metastatic breast câncer. New England Journal of Medicine 2012 Jan. Published online at http://www.nejm.org/doi/ full/10.1056/NEJMoa1113216. DOI: 10.1056/NEJMoa1113216

${ }^{14}$ Katz A, Marques R, Novis Y, Rocha V, Costa FP, Fernandes G, et al Oncologia Clínica Terapia Baseada em Evidências. $1^{\circ}$ ed., Centro de Oncologia do Hospital Sírio Libanês, São Paulo; 2012; 260-266.

${ }^{15}$ Santos, A.S. Bevacizumabe e Câncer de mama. Revi Bras de Oncologia Clínica 2014; (36): 67-70.

${ }^{16}$ American Society of Health-System Pharmacists (USA). Docetaxel Injection. U.S. National Library of Medicine 2015 mai 19. Published online at http:// www.nlm.nih.gov/medlineplus/druginfo/meds/a696031.html\#how .

${ }^{17}$ Katz A, Marques R, Novis Y, Rocha V, Costa FP, Fernandes G, et al. Oncologia Clínica Terapia Baseada em Evidências. $1^{\circ}$ ed., Centro de Oncologia do Hospital Sírio Libanês, São Paulo; 2012; 260-266.
}

that Trastuzumab directs DM1 to tumor tissues, reducing toxicity. ${ }^{18}$ The use of the medication was positive in the regression of the hepatic lesions, which corroborates for its permanence in the current therapeutic regimen.

It should be remembered, however, the prevalence of HER2 negative breast cancer in the female population as well. According to KATZ et al (2012), the treatment for HER2 negative tumors consists of the classical approach through hormone therapy with natural or synthetic hormones and chemotherapy since this tumor does not respond to Herceptin, a medicine indicated for treatment of HER2 positive.

We, therefore, conclude that the case report brings the discussion of therapeutics into a complex situation, infiltrating ductal carcinoma, and thus highlights the importance of the discussion about new systemic therapies to increase overall survival and quality of life of the patients with this tumor, especially the metastatic ones.

\section{Acknowledgements}

None.

\section{Conflict of interests}

The authors declare that they participated in the conception and contributed effectively to the accomplishment of this article. They make public the responsibility for its content, that no links or financial agreements between authors and companies that may have interest in the publication of this article have been omitted. We declare that the work is original and has not been submitted to another scientific journal and will not be as long as its publication is being considered.

\section{References}

1. Instituto Nacional de Câncer José Alencar Gomes daSilva. Estimativa 2014: Incidência de Câncer no Brasil. Rio de Janeiro: INCA; 2014.

2. Katz A, Marques R, Novis Y, et al. Oncologia Clínica Terapia Baseada em Evidências. 1st ed. São Paulo: Centro de Oncologia do Hospital Sírio Libanês; 2012. p. 260-266.

3. Cecilio AP, Takakura ET, Jumes JJ, et al. Breast cancer in Brazil: epidemiology and treatment challenges. Dove Med Press. 2015;7:43-49.

4. Santos AS. Bevacizumabe e Câncer de mama. Revi Bras de Oncologia Clínica. 2014;10(36):67-70.

5. Araujo LHL, Melo AC, Moreira MML, et al. Metástase Gástrica de Câncer de Mama: relato de caso e revisão de literatura. Revbrascancerol. 2007;53(3):365-368.

6. Kalil AN, Severa C. Hepatectomia para metástases hepáticas de câncer de mama. Rev do ColBras de Cirurgiões. 2005;32(5):285-286.

7. Neto OCLF. Metástases Hepáticas. J Bra de Medicina. 2014;(102):29-33.

8. Hoff PMG, Chammas R, Novis Y, et al. Tratado de oncologia. São Paulo: Atheneu; 2013;2860(2):2028-2029.

9. Murad AM. Tratamento do câncer de mama metastático: uma abordagem prática. Rev Bras Oncologia Clínica. 2005;1(4):29-32.

10. Machado KK, Katz A, Buyse M, et al. Sobrevida global e outros desfechos clínicos em câncer de mama: situação atual e controvérsias. Rev Assoc Med Bras. 2010;56(5):493-516.

\footnotetext{
${ }^{18}$ Katz A, Marques R, Novis Y, Rocha V, Costa FP, Fernandes G, et al. Oncologia Clínica Terapia Baseada em Evidências. $1^{\circ}$ ed., Centro de Oncologia do Hospital Sírio Libanês, São Paulo; 2012; 260-266.
} 
11. Murad AM. Tratamento do câncer de mama metastático: uma abordagem prática. Rev Bras Oncologia Clínica. 2005;1(4):29-32.

12. Katz A, Marques R, Novis Y, et al. Oncologia Clínica Terapia Baseada em Evidências. 1st ed. São Paulo: Centro de Oncologia do Hospital Sírio Libanês; 2012. p. 260-266.

13. Baselga J, Cortés J, Kim SB, et al. Pertuzumab plus Trastuzumab plus Docetaxel for metastatic breast câncer. New England Journal of Medicine; 2012.

14. Katz A, Marques R, Novis Y, et al. Oncologia Clínica Terapia Baseada em Evidências. 1st ed. São Paulo: Centro de Oncologia do Hospital Sírio Libanês; 2012. p. 260-266.
15. Santos AS. Bevacizumabe e Câncer de mama. Revi Bras de Oncologia Clínica. 2014;10(36):67-70.

16. American society of health-system pharmacists (USA). Docetaxel Injection. U.S: National Library of Medicine; 2015. 19 p.

17. Katz A, Marques R, Novis Y, et al. Oncologia Clínica Terapia Baseada em Evidências. 1st ed. São Paulo: Centro de Oncologia do Hospital Sírio Libanês; 2012. p. 260-266.

18. Katz A, Marques R, Novis Y, et al. Oncologia Clínica Terapia Baseada em Evidências. 1st ed. São Paulo: Centro de Oncologia do Hospital Sírio Libanês; 2012. p. 260-266. 